\title{
A Model for the Minimum Ignition Energy of Dust Clouds
}

\author{
Sepideh Hosseinzadeh ${ }^{\mathrm{a}}$, Jan Berghmans ${ }^{\mathrm{a}}$, Jan Degreve ${ }^{\mathrm{b}}$, Filip Verplaetsen ${ }^{\mathrm{c}}$ \\ E-mail: s.hosseinzadeh2018@gmail.com \\ ${ }^{a}$ Universiteit Leuven, Department of Mechanical Engineering, Celestijnenlann 300A, B3001 Leuven, \\ Belgium \\ ${ }^{b}$ Universiteit Leuven, Department of Chemical Engineering, Celestijnenlann 200f, B3001 Leuven, \\ Belgium
}

${ }^{c}$ Adinex NV, Brouwerijstraat 5/3, B 2200 Noorderwijk, Belgium

\begin{abstract}
:
This study refers to the minimum ignition energy (MIE) of dusts as determined by means of the Hartmann tube. To do so, six different dust with different particle size and properties are employed. A theoretical model is developed to predict the MIE based upon the physical and chemical properties of the dust. The model clearly shows the relationship between the minimum ignition energy and the minimum ignition temperature of a dust cloud. The model results in a method to calculate the MIE of dusts. Also, the time necessary for ignition can be calculated with the model. The results show that despite some limitations, the model predicts the MIE for dusts rather well. It is proposed that $40-60 \%$ energy loss would be considered when applying the model.
\end{abstract}

Keyword: Minimum Ignition Energy, Dust clouds, Minimum Ignition Temperature, Theoretical model

\section{Introduction}

Dust explosion constitute a major hazard in industries involving combustible dust materials. Many solids that are nearly nonflammable in bulk become explosive when dispersed in air as a fine powder and exposed to a suitable ignition source. Therefore, safety is of major importance when working with combustible dust as they can give rise to explosions. The risk for dust explosions can best be assessed by determining the explosion characteristics of dust. The minimum ignition energy (MIE) is a very important property for the assessment of the explosion risk of a combustible dust. It is standard procedure to determine the MIE experimentally by means of electrical discharges. The MIE is defined as the lowest energy of a high-voltage capacitor discharge that is capable of igniting a dust-air mixture. According to the thermal theory of electric spark ignition of Lewis and von Elbe (1961), immediately after discharge, the spark generates a small volume of hot gas. At the beginning, the temperature within the kernel increases but as soon as the ignition 
volume increases, due to the flow of heat to ambient, the temperature inside of kernel decreases. In the adjacent layer of ambient gas the temperature rises and induces chemical reactions, so that a combustion wave is formed and propagates outwards. At the time that the temperature within the flame kernel has decreased to the order of normal flame temperature, the diameter of the flame kernel must have grown to a certain size for self-sustained combustion, i.e. ignition, to be established. The flame kernel has more or less a spherical shape. More detailed information on spark energy and spark generation is found in (Maly, 1984; Maly and Vogel, 1979). Several factors influence the MIE such as the discharge electric circuit inductance (Eckhoff, 2003; Echhoff, 1975; Janes et al. 2008), turbulence ( Eckhoff, 2003; Guo, 2012) dust particle size (Bartknecht,1989), temperature (Eckhoff, 2003; Siwek and Cesana, 1995) and moisture content. These studies experimentally show the importance of the different parameters. A theoretical model is required to provide better insight and deeper understanding of the ignition phenomena. However, due to phenomena such as turbulence and heterogeneous combustion dust ignition is very complex. Also, Eckhoff reported that at the moment of ignition, sufficient particles arrive in the spark gap caused breakdown voltage. Then the dust particles in the neighbours of the spark are push away by the blast wave formed by highly pressurized spark channel. This results in the free zone be left around the spark. Thus, in contrast to gas combustion (Frendi and Sibulkin, 1991; Sibulkin and Siskind, 1987), only in a few studies researchers have tried to model the ignition process of the particles (Kalkert and Schecker, 1979).

In this study, the experimental determination of the MIE of a number of dusts is described. This is followed by a model of the ignition process based upon the temperature evolution of dust particles being submitted to the heat generated by the electric discharge.

\section{Experimental work}

2.1. Apparatus and test procedure

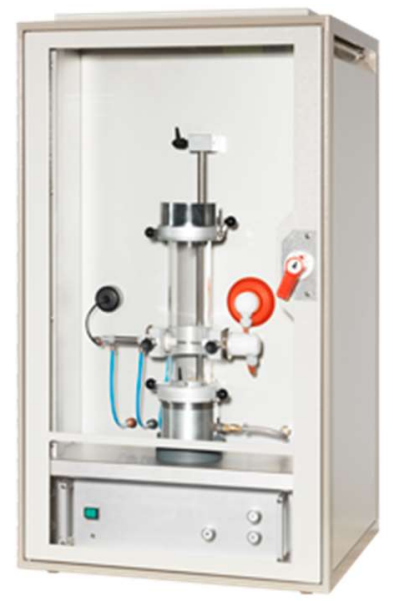

Figure 1 MIKE 3 apparatus 
In principle, the MIE lies between the lowest energy value $\left(\mathrm{E}_{2}\right)$ at which ignition occurred and the energy $\left(E_{1}\right)$ at which in at least 10 successive experiments no ignition was observed. This energy range is named the minimum ignition energy of a combustible dust in a mixture with air. Although the MIE is usually expressed as a range, in order to illustrate the behavior of the different combustible powders based on their MIE, only a single value shall be used instead of the energy range. This value can be estimated through the probability of ignition based upon equation (1) (CEN, 2003).

$$
\log M I E=\log E_{2}-I\left[E_{2}\right] \cdot \frac{\left(\log E_{2}-\log E_{1}\right)}{(N I+I) \cdot\left[E_{2}\right]+1}
$$

$I\left[E_{2}\right]$ is the number of runs with successful ignition at $E_{2}$ and $(N I+I)\left[E_{2}\right]$ stands for the total number of tests at the energy level of $E_{2}$. At least 5 concentrations need to be investigated to calculate the probability of ignition.

\subsection{Dusts investigated}

Six different dusts are investigated, as listed in Table 1. These dusts were chosen based on their particle size distribution, density and flammability. The Sebuku coal is from Indonesia which is a low sulphur and high volatile content bituminous coal. It was dried in a vacuum oven at $80^{\circ} \mathrm{C}$ and 0.1 bar until the moisture content was less than $3 \%$. The Niacin involves a very small amount of moisture. The other dusts were dry. Table 1 shows the properties of the dusts selected.

Table 1 List of dusts selected for the dusts tested

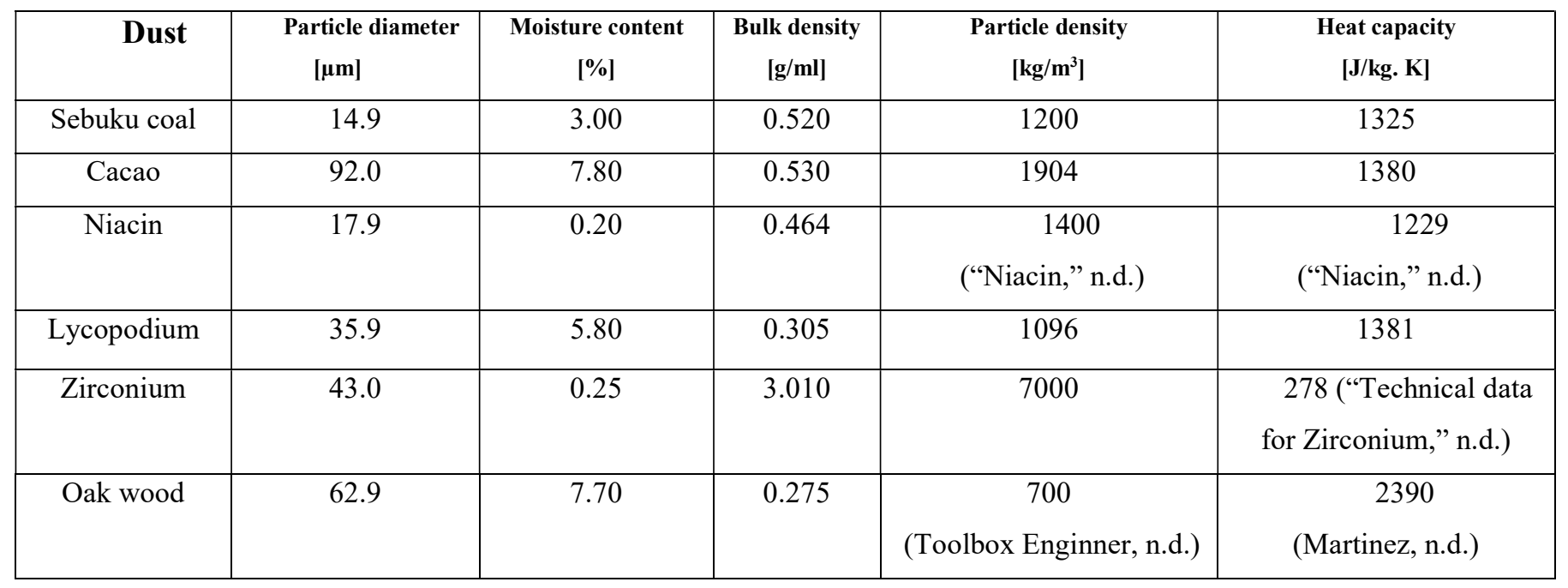

As indicated in literature (Bartknecht, 1989), the particle size or median value $\mathrm{M}$ has an influence on the minimum ignition energy. In practice, dusts normally have a broad distribution with a tail of fine particles. Such powders are more hazardous than those with the same median value but a narrow size distribution 
(Cashdollar, 2000). Therefore, for safety consideration, only fine dust with $\mathrm{M}<<63 \mu \mathrm{m}$ should be tested for the determination of the minimum ignition energy (Siwek and Cesana, 1995).

All powders were milled and sieved to produce a sufficiently fine fraction for the experiments.

Figure 2 shows the particle size distribution of the dusts as a differential distribution and as a cumulative distribution. The differential distribution shows the relative percentage of each particle size measured. The cumulative distribution reports the accumulative percentage versus particle size. The median particle size on a number basis named d50 were determined by laser diffraction analysis according to ISO 13320. It is worth noting that the zirconium particle distribution is a bimodal distribution (two peaks). The properties of the air are listed in Table 2.
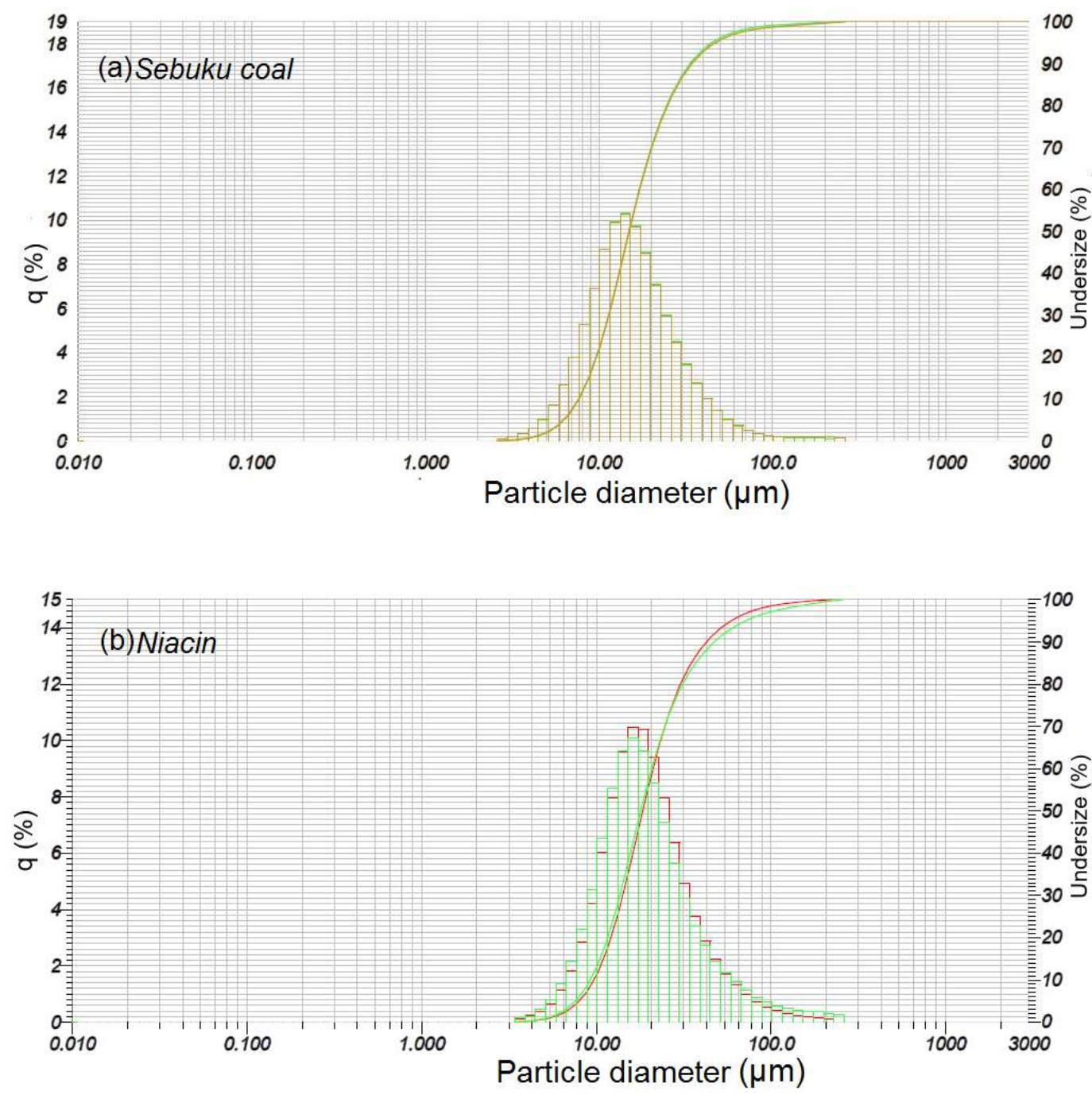

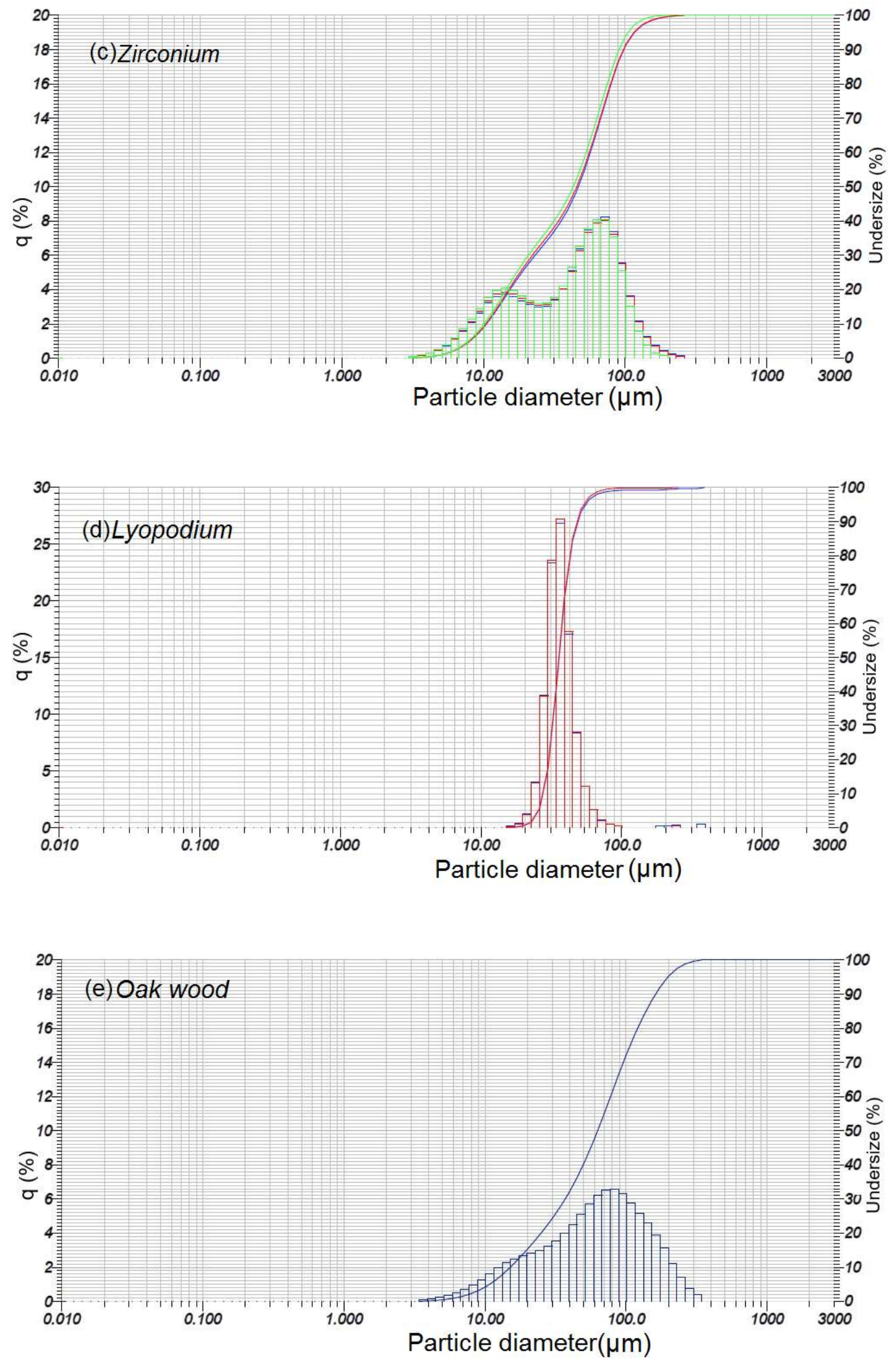


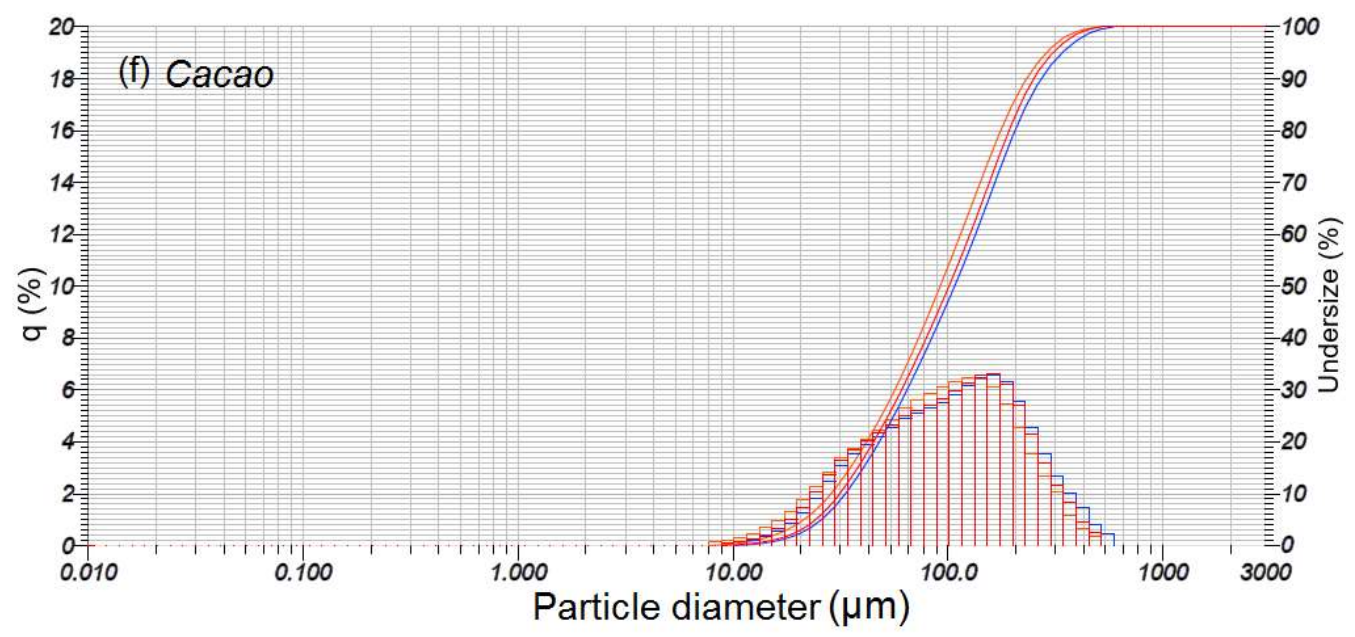

Figure 2 Particle size distribution of dust clouds, q: "diameter on cumulative \%"

Table 2 Properties of air at $25^{\circ} \mathrm{C}$ and $1 \mathrm{~atm}$

\begin{tabular}{|c|c|c|}
\hline $\begin{array}{c}\text { Density } \\
{\left[\mathbf{k g} / \mathbf{m}^{3}\right]}\end{array}$ & $\begin{array}{c}\text { Heat capacity } \\
{[\mathbf{J} / \mathbf{k g} . \mathbf{K}]}\end{array}$ & $\begin{array}{c}\text { Thermal conductivity } \\
{[\mathbf{W} / \mathbf{m} . \mathbf{K}]}\end{array}$ \\
\hline 1.205 & 1005 & 0.0257 \\
\hline
\end{tabular}

\section{Model for the minimum ignition energy}

To model the ignition process it is assumed that the spark energy is released in a small volume between the electrodes in which dust particles are present and blast wave does not exist. The heat is released instantaneously and starts to dissipate in the air outside this volume. During the process of heat diffusion, the particles present are heated up. They reach a maximum temperature and will start cooling off when the air temperature becomes lower than the particle temperature. The larger spark energy, the higher the maximum particle temperature will be. It is assumed that when the maximum temperature is equal to the auto-ignition of the particles in a dust cloud, then the particles are ignited.

The transient temperature distribution due to conduction around a point at which an amount of energy $\mathrm{E}_{0}$ is released instantaneously at time $\mathrm{t}=0$ is governed by the equation (Taler and Duda, 2006):

$$
\frac{1}{r^{2}} \frac{\partial}{\partial r}\left(k_{g} r^{2} \frac{\partial T_{g}}{\partial r}\right)+w=\rho_{g} C_{p_{-} g} \frac{\partial T_{g}}{\partial t}
$$

Where $\mathrm{kg}_{\mathrm{g}}$ is the thermal conductivity of gas, $\mathrm{T}_{\mathrm{g}}, \rho_{g}$, and $C_{p_{-} g}$ are the air temperature, the air density and the air specific heat, respectively. The term w represents the heat released. This quantity is equal to the 
minimum ignition energy $\left(E_{0}\right)$ at $t=0$ and is zero for positive times. The initial condition for Eq. (2) is $T_{g}(\mathrm{r}, 0)=\mathrm{T}_{\mathrm{i}}$, and the heat released is $\mathrm{E}_{0}$ at $\mathrm{t}=0$ at the origin.

The solution to Eq. (2) is given by (Mills, 1992):

$$
T_{g}(r, t)=T_{i}+\frac{E_{0}}{\left(4 \pi \alpha_{g} t\right)^{3 / 2} \rho_{g} C_{p_{-} g}} \exp \left(-\frac{r^{2}}{4 \alpha_{g} t}\right)
$$

Where $\mathrm{T}_{\mathrm{i}}$ is the initial temperature set equal to $300 \mathrm{k}$ and $\alpha_{g}=k_{g} / \rho_{g} C_{p_{-} g}$. At $\mathrm{r}=0$ the air temperature is given by

$$
T_{g}(0, t)=T_{i}+\frac{E_{0}}{\left(4 \pi \alpha_{g} t\right)^{3 / 2} \rho_{g} C_{p_{-} g}}
$$

This temperature is the highest temperature in the whole temperature field at any specific time. Therefore, it is to be expected that a particle at the origin will heat up faster and to a higher temperature than any other particle. Therefore, the analysis that follows is dedicated to a particle at the origin $\mathrm{r}=0$.

In order to find the temperature of a single particle with volume $\mathrm{V}$ and surface area A present at $\mathrm{r}=0$, the following assumptions are made (Kalkert and Schecker, 1979):

- The temperature around the particle is spatially uniform and equal to $T_{g}(0, t)=T_{g}$.

- The mass of the particle does not change.

- The Biot number is less than 0.2. Therefore, the temperature inside the dust particle is uniform.

A lumped-capacitance thermal balance gives (Yarin \& Hetsroni, 2004):

$$
m_{p} C_{p_{-} s} \frac{d T_{s}}{d t}=h A\left(T_{g}-T_{s}\right)
$$

Where $\mathrm{T}_{\mathrm{s}}$ is the dust particle temperature, $\mathrm{m}_{\mathrm{p}}$ is the particle mass, $C_{p_{-} s}$ is the heat capacity of the dust, $\mathrm{h}$ is the convective heat transfer coefficient and A is the particle surface area. The gas temperature from Eq. (4) is substituted into Eq. (5) giving:

$$
m_{p} C_{p_{-} s} \frac{d T_{s}}{d t}=h A\left(T_{i}+\frac{E_{0}}{\left(4 \pi \alpha_{g} t\right)^{3 / 2} \rho_{g} C_{p_{-} g}}-T_{s}\right)
$$

The convective heat transfer coefficient, $\mathrm{h}$ is given as

$$
h=\frac{N u k_{g}}{d_{p}}
$$

where $d_{p}$ and $\mathrm{Nu}$ are the particle diameter and the Nusselt number respectively. Due to the use of small particles, the Nusselt number is assumed constant $(\mathrm{Nu}=2)$ (Yarin and Hetsroni, 2004). 
At $\mathrm{t}=0$, the gas temperature $\left(\mathrm{T}_{\mathrm{g}}\right)$ at $\mathrm{r}=0$ becomes infinite, which is unrealistic. Therefore, it is assumed here that the gas temperature at the initial point of particle heating is equal to the spark temperature, which is assumed to be $2000 \mathrm{~K}$. The time to reach this value, according to equation (4) is called $\mathrm{t}_{\mathrm{g}}$. This value is only dependent on $\mathrm{E}_{0}$ and its dependence is shown in Figure 3 over a wide range of energy values.

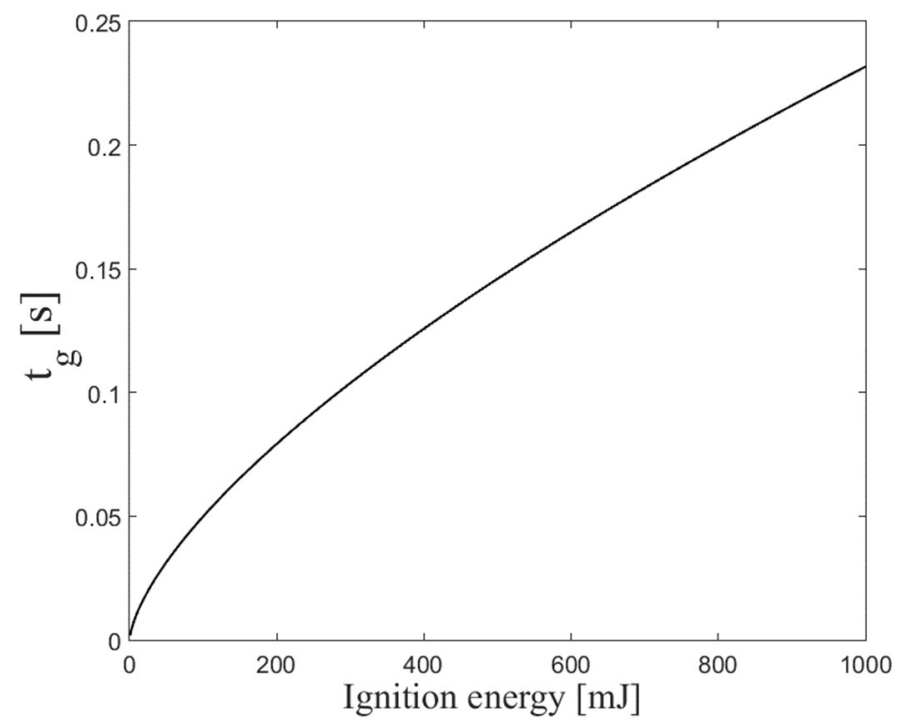

Figure 3 Time $t_{g}$ as a function of different ignition energy values; $\operatorname{tg}$ is the time required for gas to reach a temperature of $2000 \mathrm{~K}$ after sparking

The solution to the diffusion equation (3) is applied to the lumped capacity equation only for times larger than $t_{g}$. Redefining the time $t$ equation (6) becomes:

$$
m_{p} C_{p_{-} s} \frac{d T_{s}}{d t}=h A\left(T_{i}+\frac{E_{0}}{\left(4 \pi \alpha_{g}\left(t+t_{g}\right)\right)^{3 / 2} \rho_{g} C_{p_{-} g}}-T_{s}\right)
$$

The solution to Eq. (8) is given by:

$$
T_{S}(t)=\left(300 \mathrm{e}^{\mathrm{b}\left(\mathrm{t}+t_{g}\right)}+2 \mathrm{D}\left(-\frac{\mathrm{e}^{\mathrm{b}(\mathrm{tg}+\mathrm{t})}}{\sqrt{\mathrm{t}_{\mathrm{g}}+\mathrm{t}}}+\frac{\mathrm{b} \sqrt{\pi} \operatorname{erf}\left(\sqrt{-\mathrm{b}\left(t_{g}+t\right)}\right.}{\sqrt{-\mathrm{b}}}\right)-2 \mathrm{D}\left(-\frac{\mathrm{e}^{\mathrm{btg}}}{\sqrt{\mathrm{t}_{\mathrm{g}}}}+\frac{\mathrm{b} \sqrt{\pi} \operatorname{erf}\left(\sqrt{-b t_{g}}\right.}{\sqrt{-\mathrm{b}}}\right)\right) \frac{\mathrm{e}^{-\mathrm{bt}}}{\mathrm{e}^{\mathrm{btg}}}
$$

Where

$$
\begin{aligned}
& D=\frac{6 * 2 * E_{0} * \alpha_{g}}{\rho_{s} C_{p_{-} s}\left(4 \pi \alpha_{g}\right)^{\frac{3}{2}} d_{p}^{2}} \\
& b=\frac{6 * 2 * k_{g}}{\rho_{s} C_{p_{-} s} d_{p}^{2}}
\end{aligned}
$$


The heat necessary to ignite a particle is proportional to the third power of the diameter but the speed to heat up a particle is inversely proportional to the first power of the diameter. Lower heat up speed means higher MIE. So the MIE according to the model should be proportional to the diameter to a power somewhat less than 3.

It is assumed here that the MIE is the smallest value of $\mathrm{E}_{0}$ at which the maximum temperature of the particle is equal to the ignition temperature of the particle in a dust cloud (such as determined in a BAM oven).

The algorithm to calculate the MIE through Eq. (9) can be summarized as follows.

1. Assume a value for $E_{0}$

2. Find $t_{g}$ from Eq. (4) or Figure (3), where it was assumed that $T_{g}\left(t_{g}\right)=2000 \mathrm{~K}$

3. Insert $t_{g}$ and the powder properties into Eq. (9)

4. Calculate the maximum temperature $\mathrm{T}_{\mathrm{s}, \max }$

5. Compare the $\mathrm{T}_{\mathrm{s}, \max }$ with the minimum ignition temperature (MIT) experimentally determined

6. (a) If $\mathrm{T}_{\mathrm{s}, \max }$ is higher than the MIT, choose a lower value for $\mathrm{E}_{0}$, steps 2-5 are repeated until the maximum temperature of a particle becomes equal to MIT.

(b) If $\mathrm{T}_{\mathrm{s}, \max }$ is lower than the MIT, choose a higher value for $\mathrm{E}_{0}$, steps 2-5 are repeated until the maximum temperature of particle becomes equal to MIT.

The time at which the minimum ignition energy is obtained, is called $t_{s}$, the time necessary for ignition. Similar to the MIE, this value is dependent on the powder properties.

Table 3 shows the minimum ignition temperatures of the powders used in this study. 
Table 3 Minimum ignition temperature of powders

\begin{tabular}{ccc}
\hline Dust & MIT [K] & Source \\
\hline $\begin{array}{c}\text { Sebuku coal } \\
\text { Cacao }\end{array}$ & 790 & (Wu et al., 2013) \\
(Material safety data \\
sheet :Cacao powder, \\
Niacin & $760-840$ & 2010) \\
Lycopodium & 850 & (Safety Data Sheet, \\
& 680 & 2013) \\
Zirconium & & (Addai et al., 2016) \\
Oak wood & 670 & Experiment \\
& 755 & ("The Engineering \\
& & toolBox," n.d.) \\
& & \\
\hline
\end{tabular}

\section{Results and Discussion}

\subsection{Experimental Results}

Since turbulence has a significant influence on the MIE, tests should be carried out at different turbulence levels. To this purpose, tests are performed at three different delay times. In this work, three ignition delay series were applied; i.e. $90 \mathrm{~ms}, 120 \mathrm{~ms}$ and $150 \mathrm{~ms}$; or $120 \mathrm{~ms}, 150 \mathrm{~ms}$ and $180 \mathrm{~ms}$. The lowest ignition energy among these three tests series is considered to be the MIE. All tests were performed with an inductance of $1 \mathrm{mH}$. Figure 4 shows the experimental results for various dusts as a function of the dust concentration. The $x$-axis is the concentration of dust dispersed in the $1.2 \mathrm{~L}$ explosion vessel (mass/1.2 L). The y-axis shows the ignition energy. A solid dot indicates ignition and a hollow square shows that there was no ignition at that specific concentration and energy value. Figure 4 (a) illustrates that Sebuku coal is ignitable at $100 \mathrm{~mJ}$ at 5 different concentrations, whereas at $30 \mathrm{~mJ}$, it is not able to ignite. Applying Eq. (1), the MIE of Sebuku coal is equal to $55 \mathrm{~mJ}$. Similarly, Cacao is able to ignite at $1000 \mathrm{~mJ}$ within the whole range of concentrations, whereas at $300 \mathrm{~mJ}$ it is not capable of ignition at any concentration (see Figure 4b). The MIE of Cacao is, therefore, equal to $350 \mathrm{~mJ}$. The minimum ignition energy of Oak wood is equal to $42 \mathrm{~mJ}$ (Figure 4c). In addition, it is seen in Figure $4 \mathrm{~d}$ that Zirconium is able to ignite at $1 \mathrm{~mJ}$ at one concentration. Consequently, its MIE is outside the range of the MIKE 3-apparatus. Table 4 gives a summary of the results. 

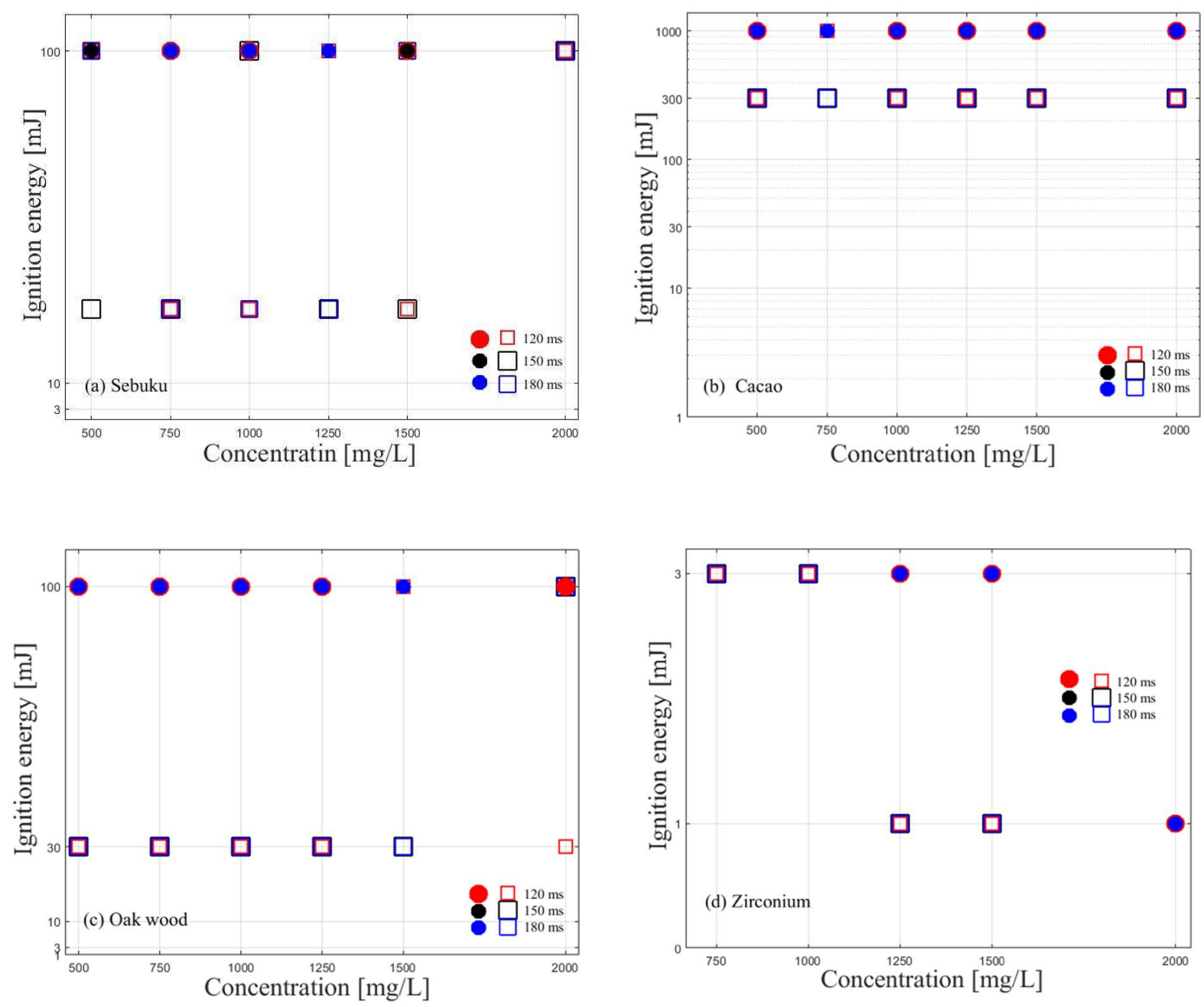

Figure 4 Ignition energy as a function of dust concentration loaded in the MIKE3 apparatus (a) Sebuku coal (b) Cacao (c) Oak wood (d) Zirconium. A solid dot indicates ignition and a hollow square shows that there was no ignition at that specific concentration and energy value

Table 4 Minimum ignition energy of powders

\begin{tabular}{|l|l|}
\hline \multicolumn{1}{|c|}{ Dust } & MIE (mJ) \\
\hline Sebuku & 55 \\
Niacin & 1.6 \\
Cacao & 350 \\
Lycopodium & 4 \\
Oak wood & 42 \\
Zirconium & $<1$ \\
\hline
\end{tabular}


The difference in MIE of the substances (Table 4) can be attributed to several properties. First, an increase in the dust particle size decreases the surface area exposed to ignition and consequently the MIE increases (Cesana and Siwek, 2001). Secondly, dusts with higher volatility are more prone to ignition. In fact, a dust with more volatile content tends to produce more combustible gas which leads to easier combustion. In addition, the moisture content of powder plays an important role.

\subsection{Model evaluation}

Table 5 compares the minimum ignition energies obtained from the model with those determined experimentally. It was pointed out above that the particle size distribution for zirconium has two-peaks. It is expected that finer particles are prone to ignition easier than heavier ones. Therefore, the first peak, 13 $\mu \mathrm{m}$, is the diameter responsible for ignition initiation leading to minimum ignition energy of $0.33 \mathrm{~mJ}$.

Table 5 Comparison of MIE obtained experimentally and Eq. (10)

\begin{tabular}{|cccc|}
\hline Substance & $\begin{array}{c}\text { MIE (mJ) } \\
\text { experimental }\end{array}$ & $\begin{array}{c}\text { MIE (mJ) } \\
\text { Eq. }(9)\end{array}$ & $\begin{array}{c}\text { Time required to } \\
\text { ignite, } \mathrm{t}_{\mathrm{s}}(\mathrm{ms})\end{array}$ \\
\hline Zirconium & $<1$ & 0.33 & 2 \\
Niacin & 1.6 & 1 & 4 \\
Lycopodium & 4 & 1.6 & 7 \\
Oak wood & 42 & 15 & 21 \\
Cacao & 350 & 140 & 73 \\
Sebuku coal & 55 & 0.4 & 3 \\
\hline
\end{tabular}

Figure 5 compares the experimental MIE versus the calculated ones. Since several parameters influence the minimum ignition temperature, inaccuracies will exist in the values of Table 5. Therefore, the error bars present the effect of $\pm 50 \mathrm{~K}$ minimum ignition temperature variation on the MIE that was calculated and the results are indicated as error bars in Figure 5. The red line stands for conditions where experimental and model data are equal.

Table 5 indicates that for Sebuku coal, the minimum ignition energy obtained through the model proposed is much lower than the one obtained experimentally. This is also clearly seen in Figure 5. This can be attributed to the complicated combustion process of the coal. Coal contains a volatile material that is released at a low temperature. It is this gas that is ignited and the combustion in the beginning is in the gas phase while gas is generated from inside a particle. Afterwards, the combustion proceeds inside the particle itself. The model proposed assumes that the combustion occurs spontaneously in the particle. 


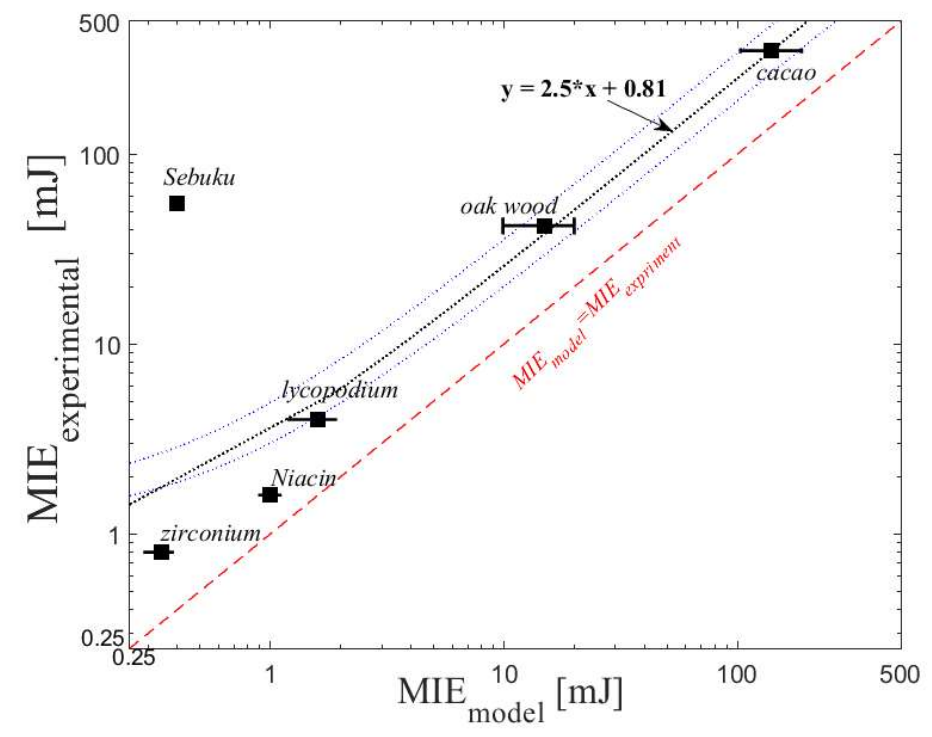

Figure 5 Comparison of the experimental MIE values versus the ones obtained through our model for various powders

The data of cacao, wood and lycopodium express that the experimental values are around 2.5 times bigger than those obtained through Eq. (9). For niacin, the experimental value is 1.6 times bigger than what the model proposed. This difference can be attributed to several parameters which are not taken into account in the model. These include: the electrical energy dissipation into the electrodes, energy loss due to radiation from the spark to the surroundings and conduction losses to the electrodes. In addition, there are the assumptions made in the model about particle shape, cloud ignition temperature etc. The contribution of these uncertainties cannot be separately distinguished. However Eisazadeh-far (Eisazadeh-Far et al., 2010) reported that radiation can dissipate $20 \%-60 \%$ of discharge energy depending on spark duration and spark temperature. Also in their work, 25-30\% of discharge energy was dissipated by the cathode conduction and the thermal boundary layer. Finally, they concluded that only 10-25\% of discharge energy is converted to thermal energy. Teets and Sell (Teets and Sell, 1988) indicated that the largest fraction of energy dissipation is due to conduction losses to the electrodes. Belinger et al. (Belinger et al., 2011) focused on one value of ignition energy $(55 \mathrm{~mJ})$ and they found that half of the total energy is lost during ignition. Beloni (Beloni, 2011) reported that the minimum ignition energy of $\mathrm{Mg}$ is $25 \mathrm{~mJ}$ and the predicted spark energy to this powder is $11 \mathrm{~mJ}$ which indicates that $56 \%$ of spark energy is lost. He also compared the predicted energy delivered to the particle with the total spark energy for several dusts and he concluded that the measured heat energy varies from 50 to $90 \%$ of the total spark energy. Hertzberg et al. (Hertzberg et al.1985) introduced an effective spark energy based on the pressure rise $\Delta P$ generated by the spark discharge in a chamber of constant volume $(\mathrm{V})$ : 


$$
E_{\text {effective }}=2.5 \Delta P \mathrm{~V}
$$

They applied their model to several dusts in the Hartmann tube. Their results showed that the effective energy for lycopodium and polyethylene is $40 \%$ and for Pittsburgh coal $75 \%$ less than the capacitance energies.

The black line in Figure 5 shows that there is $60 \%$ discrepancy between the experimental results and the model ones. For Niacin, the discrepancy is $40 \%$. This can be attributed to its short ignition time which allows less time for energy losses during ignition (Hosseinzadeh, 2018). Table 5 also shows the time required for ignition for different powders. Except for Sebuku coal, this table suggests that as the MIE of a dust decreases, the time taken for the combustion to start ignition also decreases.

Kalkert et al. (Kalkert and Schecker, 1979) proposed a model based on the physical properties of one single particle. They proposed the following expression to calculate the MIE of dusts in air:

$$
E_{0}=\left(4 \pi k_{g}\right)^{\frac{3}{2}} \rho_{g} C_{p_{-} g}\left[\frac{\ln 2 \rho_{s} C_{p_{-} s}}{12 k_{g}}\right]^{3 / 2} T_{\max } d_{p}{ }^{3}
$$

$\mathrm{T}_{\max }$ is defined as the gas temperature around a particle at ignition time assumed to be $1000{ }^{\circ} \mathrm{C}$ (Kalkert and Schecker, 1979).

Figure 6 compares the experimental results obtained with the semi-quantitative model developed by Kalkert (Kalkert \& Schecker, 1979) and our present model. To use the model proposed, the value resulting from Eq. (9) should be multiplied by 2.5. It is clearly seen that the experimental data are very close to data provided by Eq. (9). Although there is no experimental value for MIE of zirconium, Eq. (9) predicts a value of $1 \mathrm{~mJ}$ while the experimental value is less than $1 \mathrm{~mJ}$. Figure 6 shows that the Kalkert model predicts values that are far from the experimental ones. 


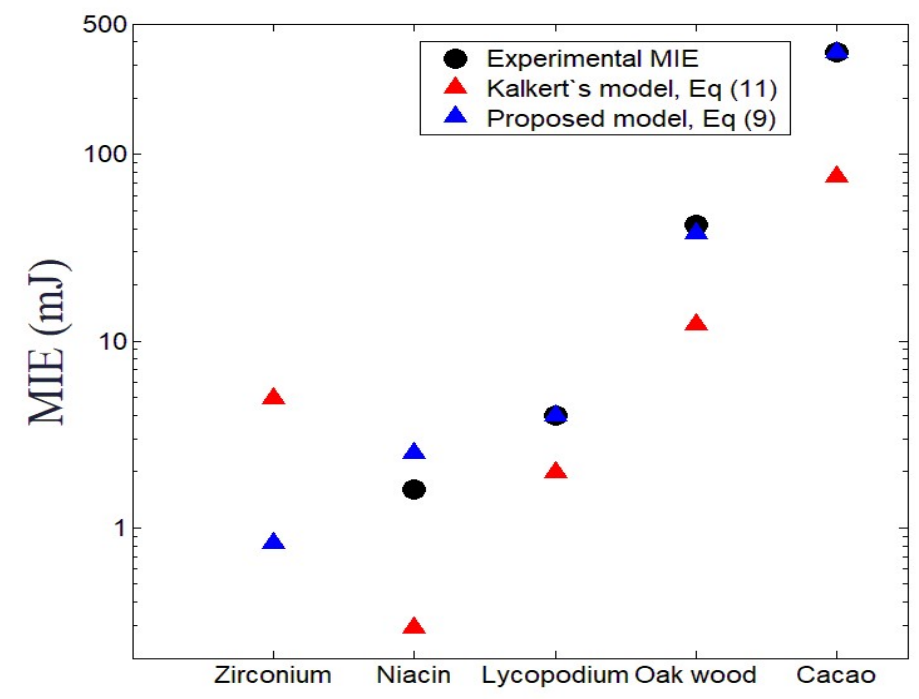

Figure 6 Comparison of experimental minimum ignition energy (MIE) of dust with corrected theoretical models where a $50 \%$ loss of spark energy is incorporated

\section{Conclusions}

In the present study, the minimum ignition energy of several dusts is determined in the Hartmann tube. It is observed that the minimum ignition energy of dusts varies over a wide range of values. A model of the ignition process is developed, based upon the thermal behavior of particles submitted to the heat of the discharge. It results in MIE values that are close to the observed ones when heat losses from the discharge are accounted for. It is proposed to incorporate a 40-60\% energy loss when applying the model.

Note: This research did not receive any specific grant from funding agencies in the public, commercial, or not-for-profit sectors. 


\section{References}

Addai, E. K., Gabel, D., Krause, U. (2016). Experimental investigation on the minimum ignition temperature of hybrid mixtures of dusts and gases or solvents. Journal of Hazardous Materials, 301, 314-326. https://doi.org/http://dx.doi.org/10.1016/j.jhazmat.2015.09.006

Bartknecht, W. (1989). Dust Explosions: Course, prevention, protection. London: Springer London.

Belinger, A., Hardy, P., Barricau, P., Cambronne, J. P., Caruana, D. (2011). Influence of the energy dissipation rate in the discharge of a plasma synthetic jet actuator. Journal of Physics D: Applied Physics, 44(36), 365201. https://doi.org/10.1088/0022-3727/44/36/365201

Beloni, E. (2011). Study of the Heating and Ignition of Metal Powder By Electrostatic Discharge.PhD diss. New Jersey Institute of Technology.

Cashdollar, K. L. (2000). Overview of dust explosibility characteristics. Journal of Loss Prevention in the Process Industries, 13(3-5), 183-199. https://doi.org/10.1016/S0950-4230(99)00039-X

CEN. (2003). Potentially explosive atmospheres, Explosion prevention and protection, Determination of minimum ignition energy of dust /air mixtures, European Standard EN 13821. Brussels.

Cesana, C.,Siwek, R. (2001). MIKE 3, Minimum ignition energy. B021_032, Adolf Kuhner AG ,Switzerland.

Eckhoff, R. (1975). Towards absolute minimum ignition energies for dust clouds? Combustion and Flame, 24, 53-64. https://doi.org/10.1016/0010-2180(75)90128-5

Eckhoff, R. K. (2003). Dust Explosions in the Process Industries (3rd ed.). Gulf Professional Publishing.

Eisazadeh-Far, K., Parsinejad, F., Metghalchi, H., Keck, J. C. (2010). On flame kernel formation and propagation in premixed gases. Combustion and Flame, 157(12), 2211-2221. https://doi.org/http://dx.doi.org/10.1016/j.combustflame.2010.07.016

Frendi, A., Sibulkin, M. (1991). Extinction of methane oxygen mixtures by nitrogen dilution. Combustion and Flame, 86(1), 185-186. https://doi.org/http://dx.doi.org/10.1016/00102180(91)90066-K

Guo, X. (2012). Oxy-fuel Combustion: Dust Explosion Characteristics of Pulverized Coal. MS diss K.U.Leuven.

Hertzberg, M., Conti, R., Cashdollar, K. (1985). Spark Ignition Energies for Dust-Air Mixtures: Temperature and Concentration Dependencies. Twentieth Symposium (International) in Combustion. Pittsburgh,: The Combustion Institute, 1681-1690

Hosseinzadeh, S. (2018). Study of dust explosion characterustics and their determination.PhD diss, KU Leuven.

Janes, a, Chaineaux, J., Carson, D., Le Lore, P. a. (2008). MIKE 3 versus HARTMANN apparatus: comparison of measured minimum ignition energy (MIE). Journal of Hazardous Materials, 152(1), 32-39. https://doi.org/10.1016/j.jhazmat.2007.06.066

Kalkert, H. G., \& Schecker, N. (1979). Theoretische Überlegungen zum Einfluß der Teilchengröße auf die Mindestzündenergie von Stäuben. Chemie Ingenieur Technik, 51(12), 1248-1249.

Maly, R. (1984). Spark Ignition: Its Physics and Effect on the Internal Combustion Engine. In J. C. Hilliard \& G. S. Springer (Eds.), Fuel Economy: in Road Vehicles Powered by Spark Ignition Engines (pp. 91-148). Boston, MA: Springer US. https://doi.org/10.1007/978-1-4899-2277-9_3 
Maly, R., Vogel, M. (1979). Initiation and propagation of flame fronts in lean CH4-air mixtures by the three modes of the ignition spark. Symposium (International) on Combustion, 17(1), 821-831. https://doi.org/http://dx.doi.org/10.1016/S0082-0784(79)80079-X

Martinez, I. (n.d.). Properties of solids. Retrieved April 20,2017, from http://webserver.dmt.upm.es/ isidoro/dat1/eSol.pdf.

Material safety data sheet :Cacao powder. (2010). Retrieved July 1, 2017, from http://formulatorsampleshop.com/

Mills, A. (1992). Heat transfer. Richard D. Irwin,Boston: CRS Presee.

Niacin. (n.d.).

Safety Data Sheet.(2013). Retrieved from http://jubl.com/1si/uploads/files/133msds_Niacin.pdf

Sibulkin, M., Siskind, K. S. (1987). Numerical study of initiation of a combustion wave by an ignition kernel. Combustion and Flame, 69(1), 49-57. https://doi.org/http://dx.doi.org/10.1016/00102180(87)90020-4

Siwek, R., Cesana, C. (1995). Ignition behavior of dusts: Meaning and interpretation. Process Safety Progress, 14(2), 107-119. https://doi.org/10.1002/prs.680140205

Taler, J., Duda, P. (2006). Approximate Analytical Methods for Solving Transient Heat Conduction Problems. In Solving Direct and Inverse Heat Conduction Problems (pp. 587-604). Berlin, Heidelberg: Springer Berlin Heidelberg. https://doi.org/10.1007/978-3-540-33471-2_20

Technical data for Zirconium. (n.d.). Retrieved April 22, 2017, from http://periodictable.com/Elements/040/data.html

Teets, R. E., \& Sell, J. A. (1988). Calorimetry of Ignition Sparks. In SAE Technical Paper. SAE International. https://doi.org/10.4271/880204

The Engineering toolBox. (n.d.). Retrieved April 22, 2017, from http://www.engineeringtoolbox.com/wood-density-d_40.html

Toolbox Enginner. (n.d.). http://www.engineeringtoolbox.com/fuels-. Retrieved April 20, 2017, from http://www.engineeringtoolbox.com/fuels-ignition-temperatures-d_171.html.\%0D

Wu, D., Norman, F., Verplaetsen, F., Berghmans, Jan, \& Van Den Bulck, E. (2013). Experimental analysis of minimum ignition temperature of coal dust clouds in oxy-fuel atmospheres. In The 6th Clean Coal Technologies Conference. Thessaloniki.

Yarin, L. P., Hetsroni, G. (2004). Dynamics of a single particle. In Combustion of Two-Phase Reactive Media (pp. 1-298). Berlin, Heidelberg: Springer Berlin Heidelberg. https://doi.org/10.1007/978-3662-06299-9_1 